\title{
Methane Source Attribution Challenges in the Surat Basin, Australia
}

\author{
Xinyi Lu (Lexie) ${ }^{1}$ \\ Bryce Kelly 2 \\ Stephen Harris
}

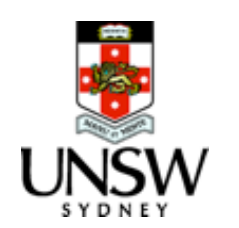

Jorg Hacker

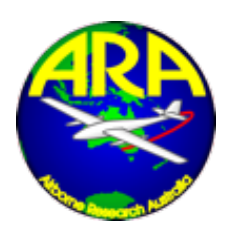

Airborne Research Australia

Non-Profit Research Institute
Rebecca Fisher
Dave Lowry
James France

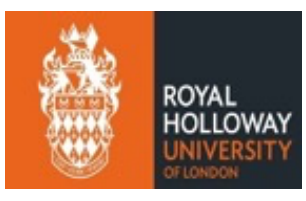

Bruno Neininger

$$
\begin{gathered}
\text { Met } 4 \text { irr } \\
\text { airborne research } \\
\text { Switzerland }
\end{gathered}
$$

Thomas Röckmann

Carina van der Veen

Malika Menoud

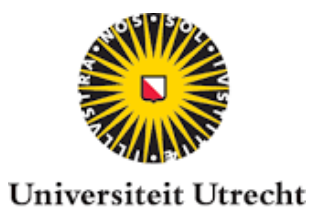

Stefan Schwietzke

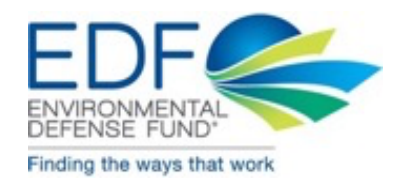


CLIMATE 8 CLEAN AIR COALITION

TO REDUCE SHORT-LIVED CLIMATE POLLUTANTS

\title{
Oil and Gas Methane Science Studies
}

\author{
Christopher Konek \\ Christopher.konek@un.org
}

This project is part of the CCAC Methane Science Studies

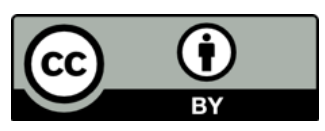




\section{Study Background}

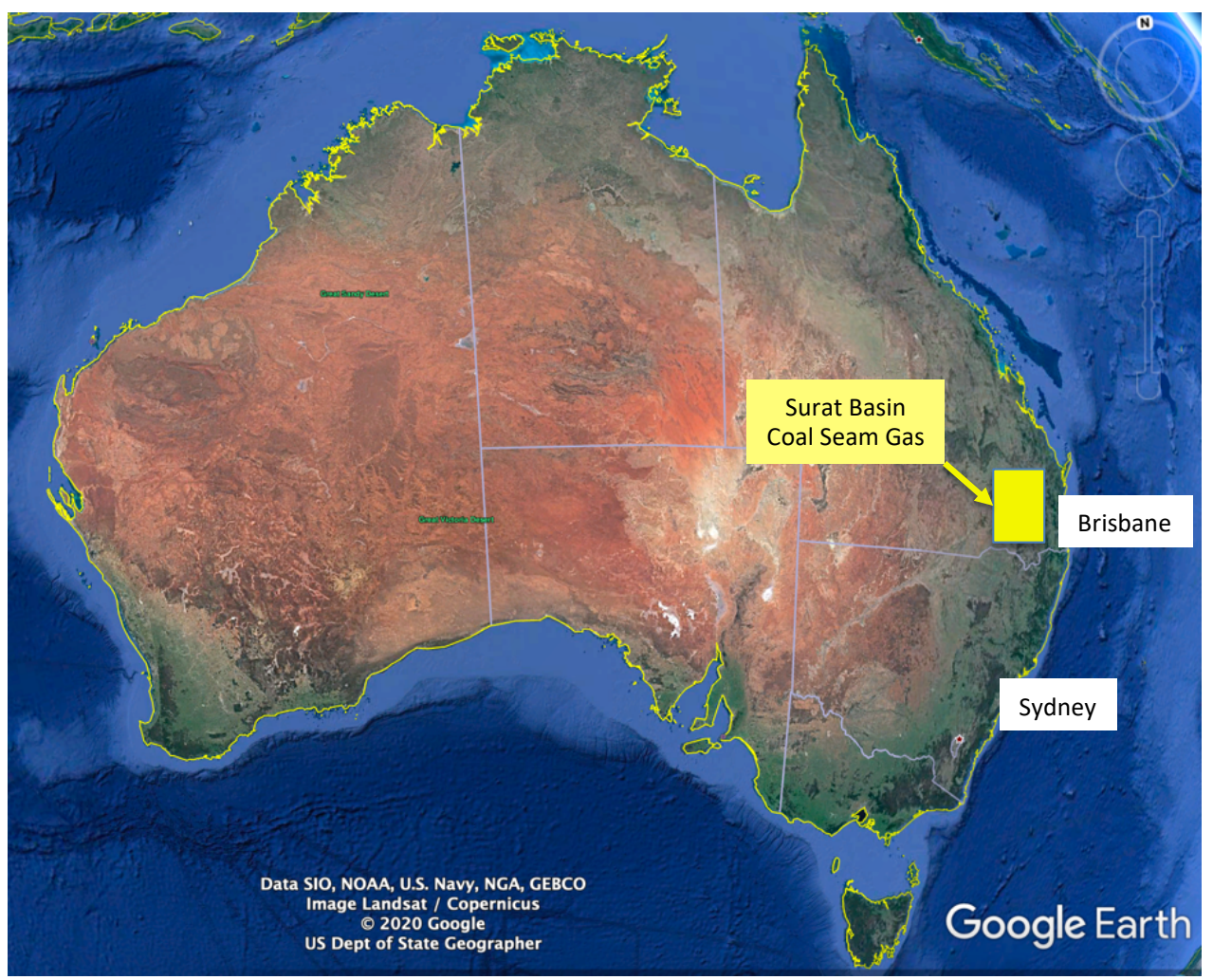

The Surat Basin is one of the largest coal seam gas (CSG) developments in the world. It is anticipated that when fully developed there will be over 20,000 CGS wells and supporting infrastructure. In 2018 the total gas produced was $8912 \mathrm{Mm}^{3}$.(data.qld.gov.au).

Our study area extends north west of Toowoomba and covers an area of approximately $200 \mathrm{~km} \times 200 \mathrm{~km}$.

There are limited emission data in the public domain:

- CSIRO Surat Basin tower inversion study (Luhar et al. 2018).

- Katestone bottom-up inventory (appendix Luhar et al. 2018).

- Ground-based measurement surveys (See Nisbet et al. (2020) for 2014 Google Earth displays of the methane emissions in the region. https://doi.org/10.1029/2019RG000675

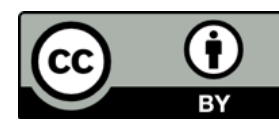




\section{Study Aim}

- Our overall aim of the CCAC Methane Science Study in the Surat Basin is to quantify the methane emissions from coal seam gas production and processing. However, in the Surat Basin there are many sources of methane. The primary source of methane based on the 2018 CSIRO / Katestone study is cattle (a combination of feedlot and grazing cattle). See Luhar et al. (2018).

- To correctly apportion methane emissions to each sector from our airborne measurements we need to be able to separate contributions from all sources. This is being achieved using a combination of:

- Ground surveys using a car-mounted LGR greenhouse gas analyzer

- Airborne surveys using a wing-mounted LGR greenhouse gas analyzer

- Isotopic chemical analyses of ground and airborne collected air samples

- We have also collated our own bottom-up inventory using IPCC and Australian Government emission factors applied to public domain production data for gas, coal, agricultural and urban sources. This inventory was tabulated to guide both the airborne- and groundbased studies.

- This presentation covers how we characterized the isotopic chemistry of methane for all primary sources and demonstrates the need for comprehensive quality control steps.

- During spring in Queensland the ground surface is rapidly warmed after sunrise. The warm ground heats the air near the ground surface and this air rises rapidly and mixes with the fresh background air (mean $\left[\mathrm{CH}_{4}\right]=1.8015 \mathrm{ppm}, 2 * \mathrm{Std}$ Dev $=0.0008$. Established using 2500 LGR greenhouse gas analyzer measurements, calibrated to CSIRO southern ocean air standard $1.80055+/-0.00007$ ppm). The maximum concentration recorded for our airborne collected grab bag samples was 1.864 ppm (collected $130 \mathrm{~m}$ above a feedlot). We show that with rigorous quality control we can use $\delta^{13} C_{-} \mathrm{CH}_{4}$ and $\delta \mathrm{D}_{-} \mathrm{CH}_{4}$ to assist with source apportionment. The error in the reported $\delta D$ is $\pm 1.5 \%$; in $\delta^{13} \mathrm{C} \pm 0.08 \%$ for the bag samples. 


\section{Background - Gas Wells}

A tiny portion of the $>4000$ wells in our region of study.

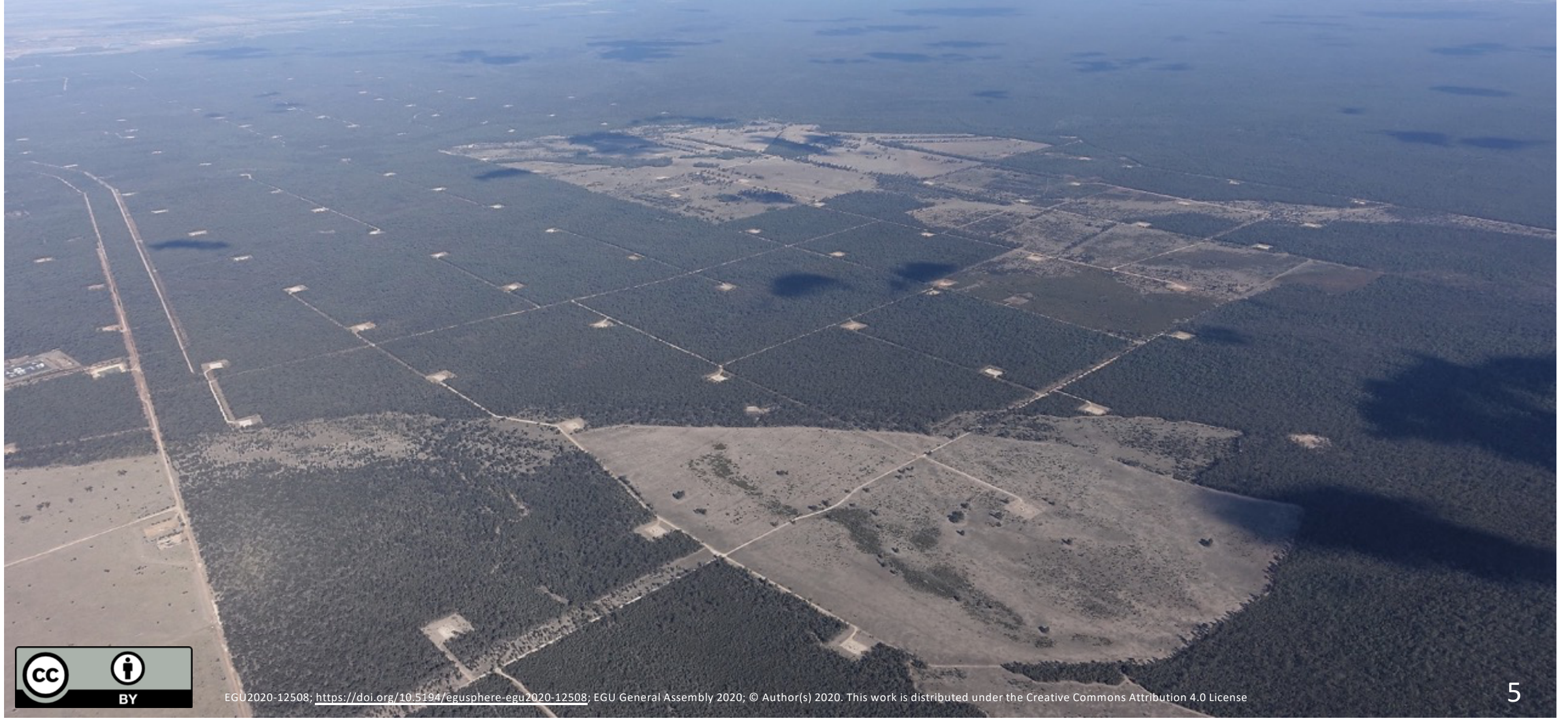




\section{Background-Typical Gas Facilities}

There are 27 CSG facilities: gas compressor stations and processing plants.

In addition to emissions from the CSG facilities, we have mapped emissions from the water pipeline high point vents and the raw water holding ponds.

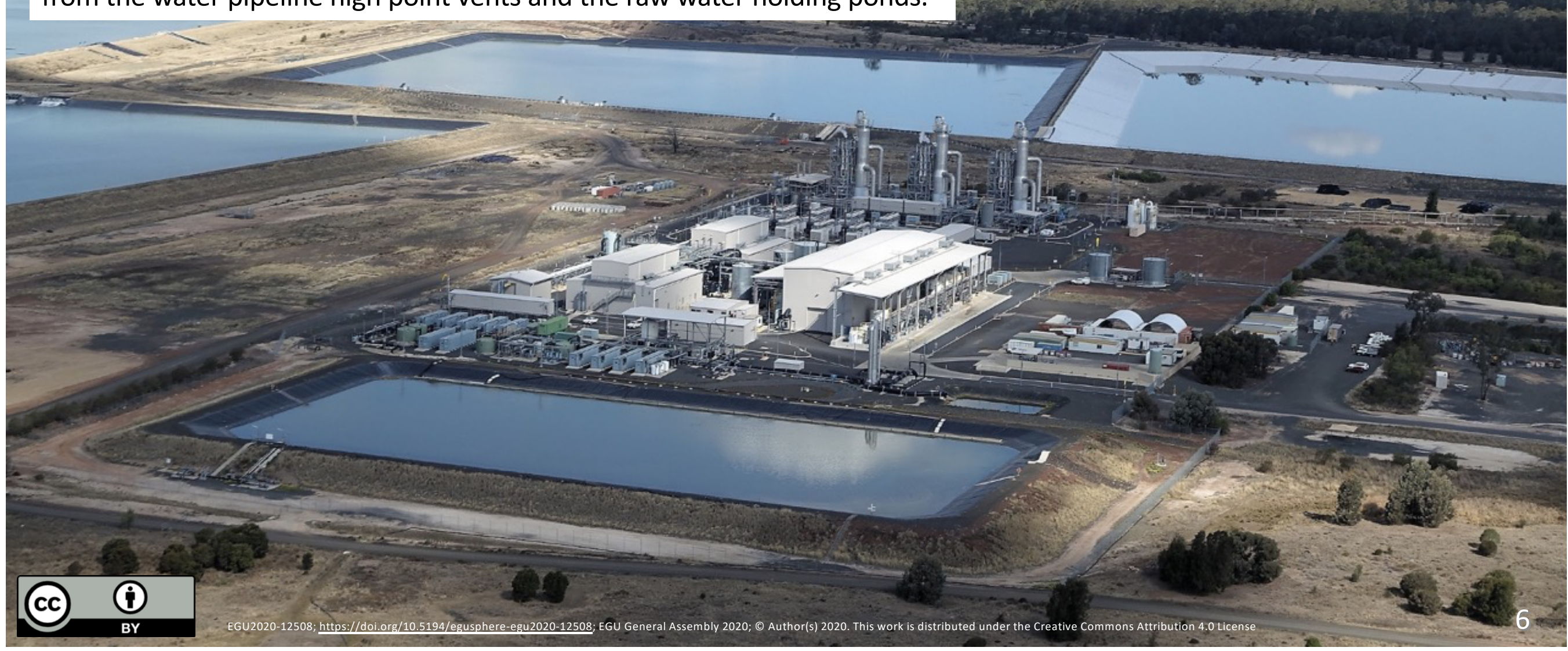




\section{Background - Feedlot}

There are 55 cattle feedlots in the area. The largest feedlot can hold 70,000 animals.

Many of the feedlots use the groundwater produced in association with extracting the gas.

There are also 1.8 million grazing cattle throughout the region.

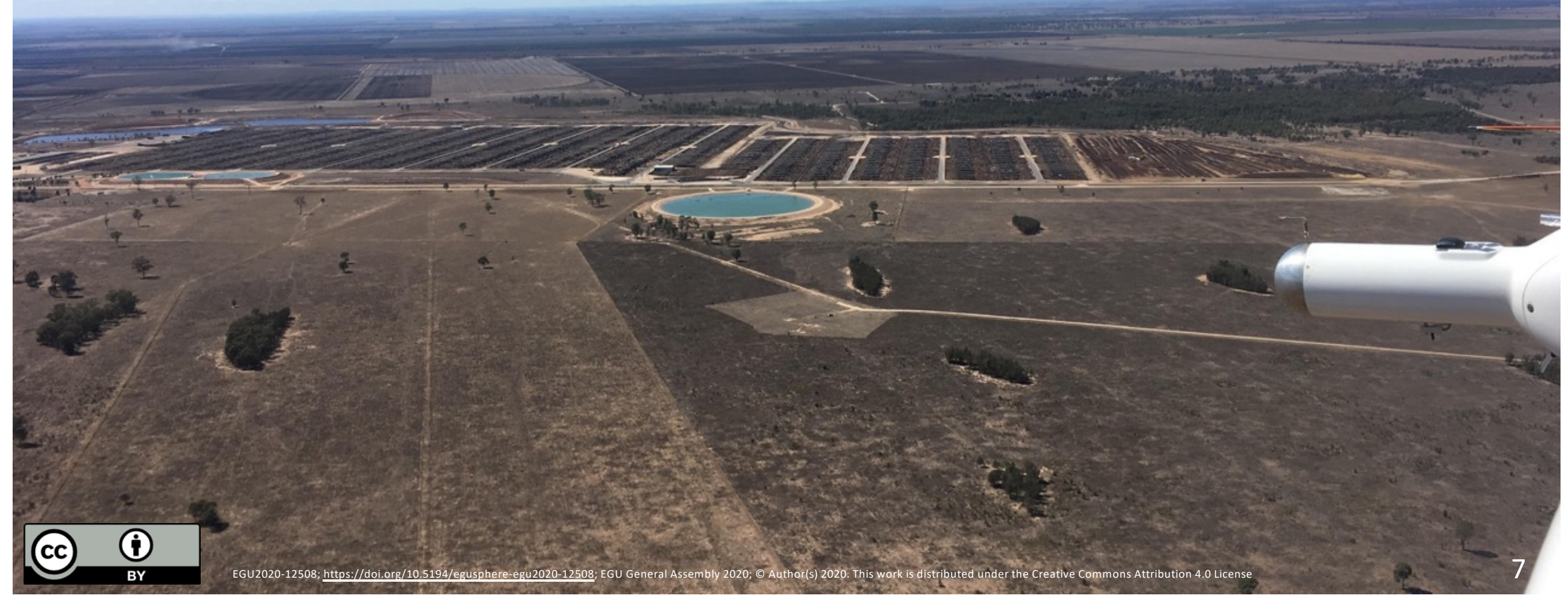




\section{Many sources have high nighttime methane mole fraction plumes}

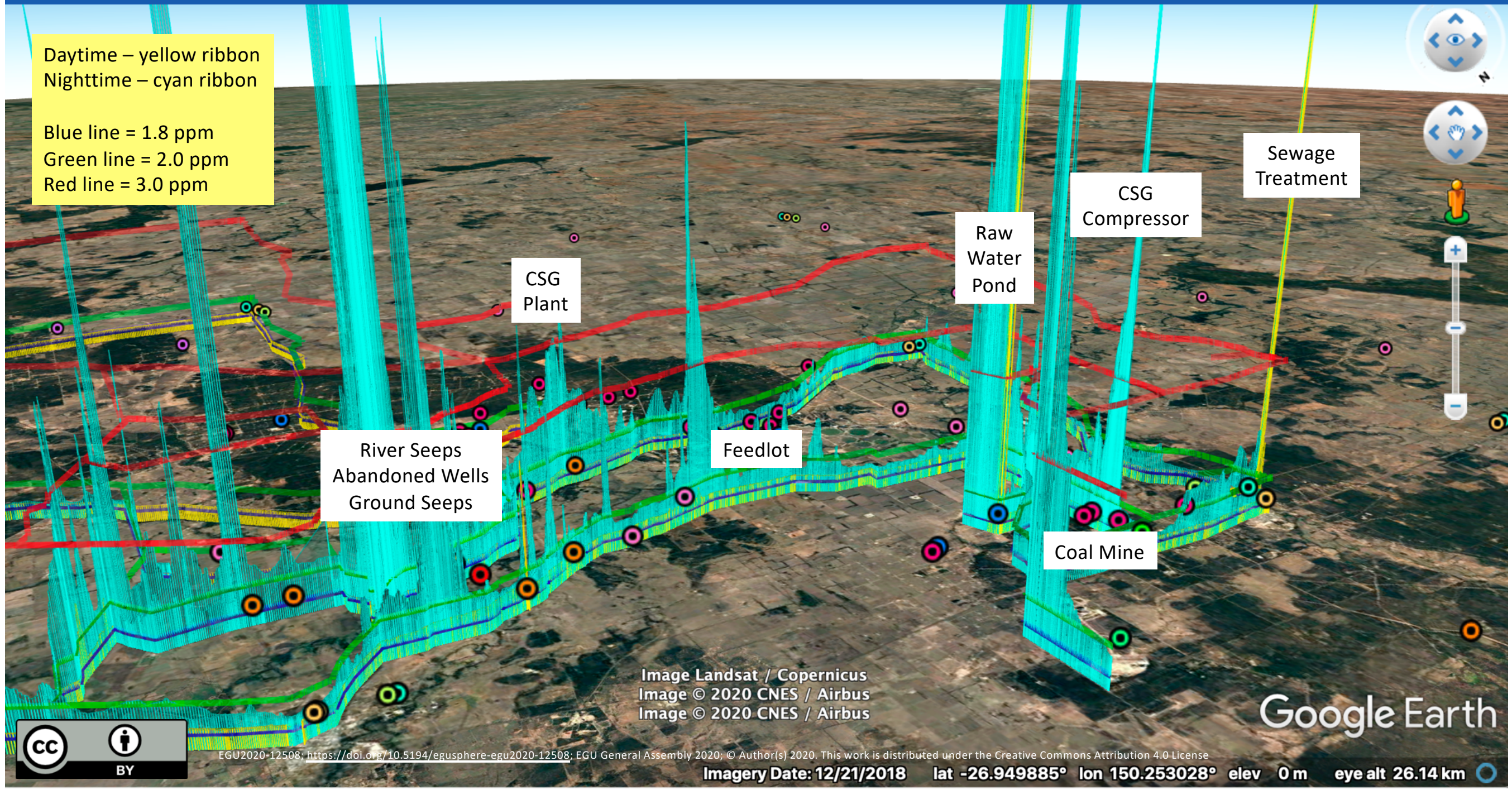




\section{Inventory - Point Sources of Methane}

Over 4600 wells have been drilled in the study region as part of exploration and development operations, and in 2018 there were approximately 1300 producing wells in the study area.

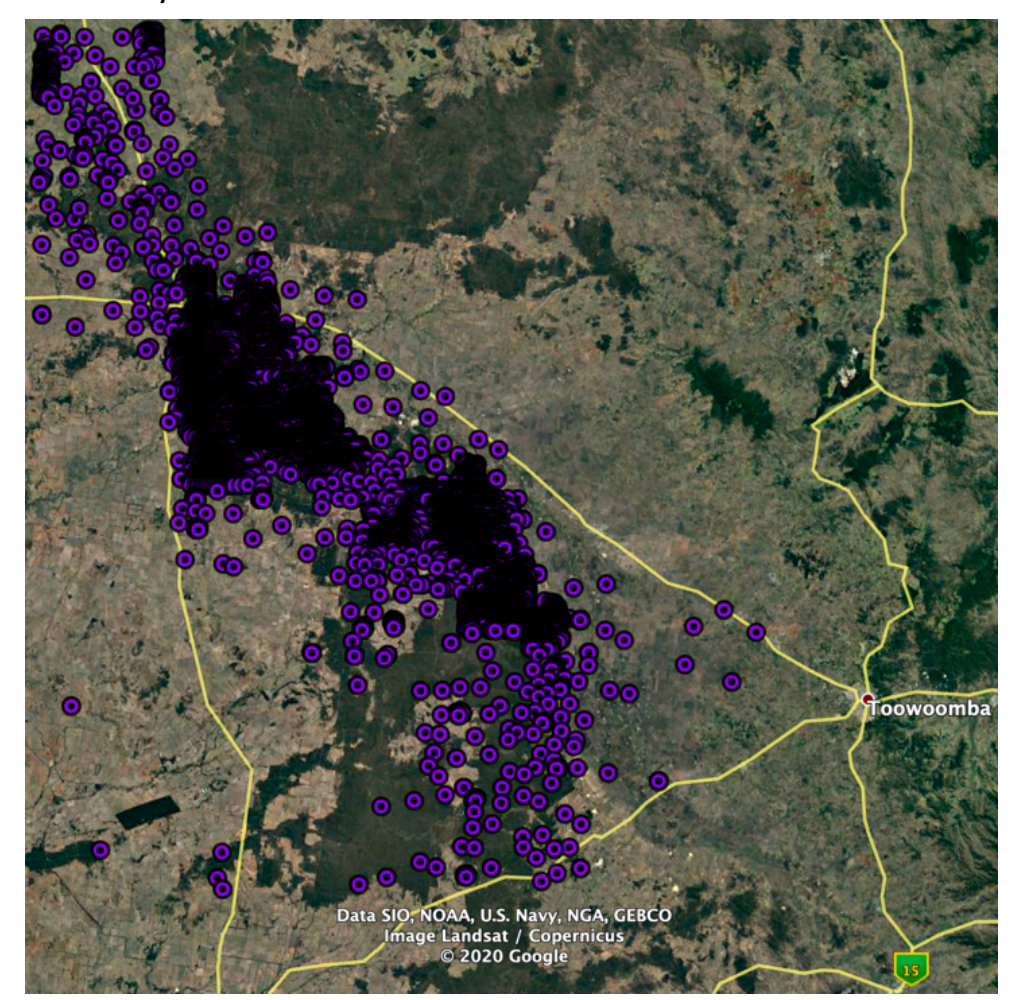

Approximately 300 methane point sources have been identified from Google Earth, government data sets, listed companies' annual reports, and environmental impact statements.

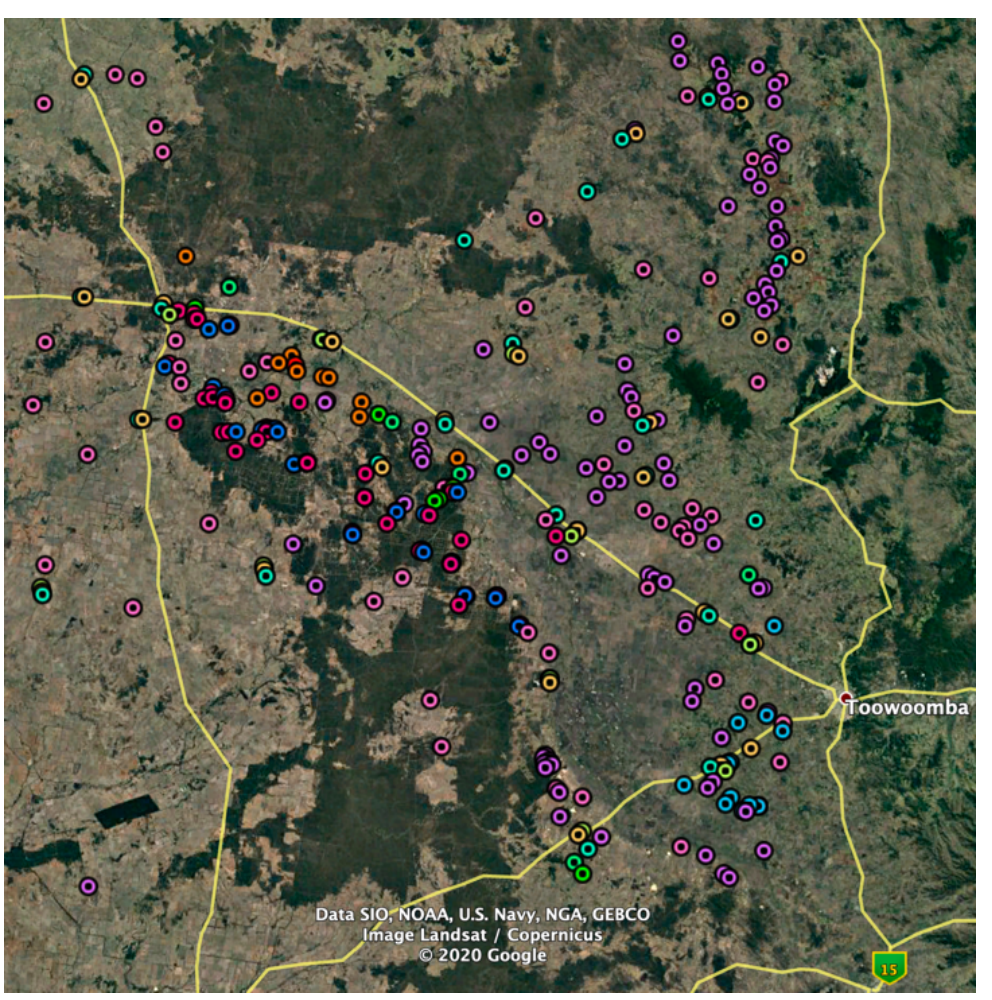

Sources:

CSG plants

CSG compressor facilities

CSG raw water ponds

Coal mines

Power stations

Ground seeps of unknown origin

Historical exploration wells seeps

River gas seeps

Cattle feedlots

Piggeries

Poultry farms

Landfills

Waste-water treatment plants

Domestic wood fires

Mixed urban emissions

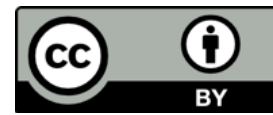




\section{Inventory - Diffuse Sources of Methane}
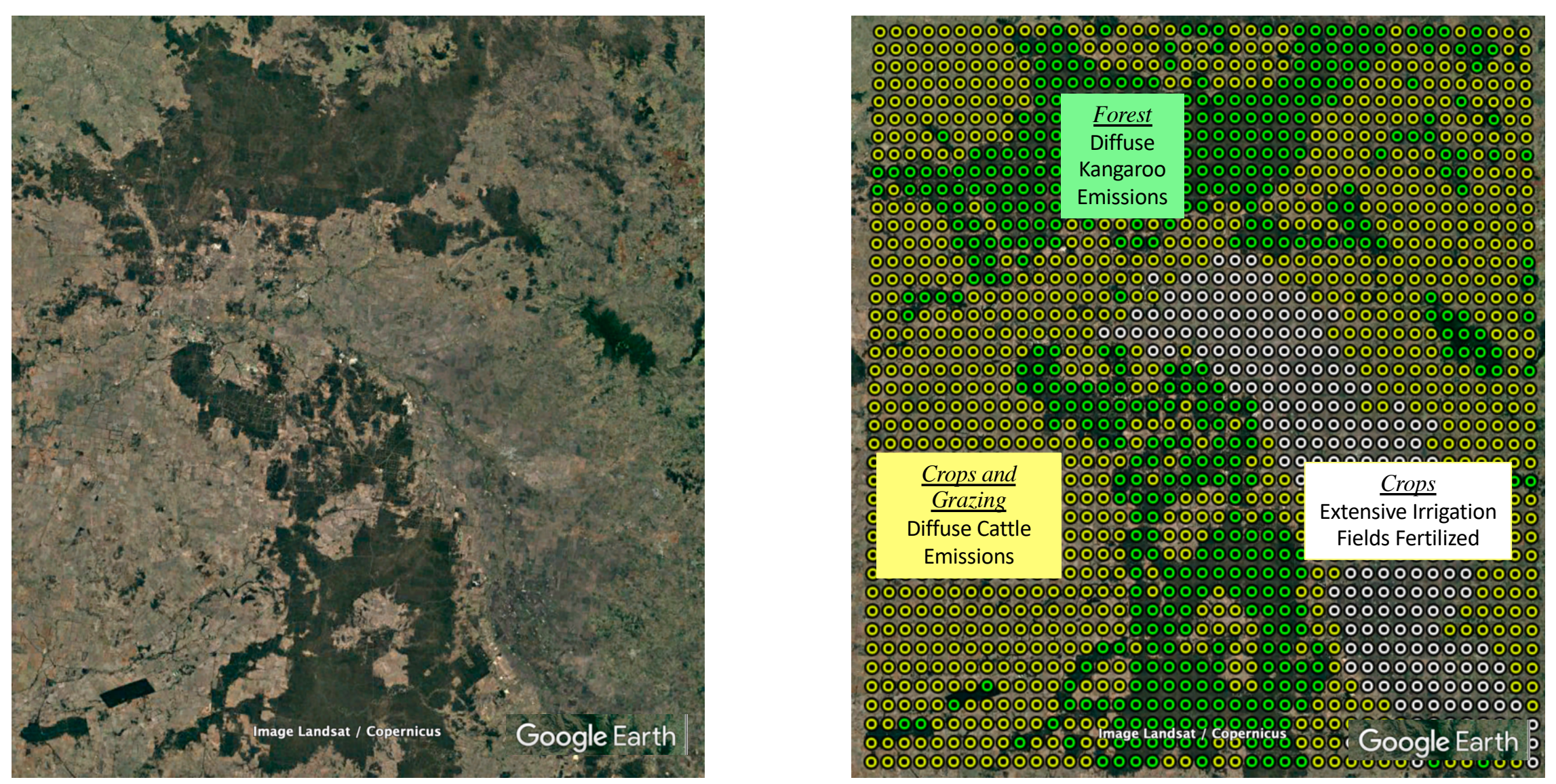


\section{Methodology Workflow for Source Apportionment}

Red text and boxes - Isotope study

Blue text and boxes - Airborne methane flux quantification. See Neininger et al. (2020) https://doi.org/10.5194/egusphere-egu2020-10993

Black boxes and text - Inventory using IPCC \& Australian Government emission factors
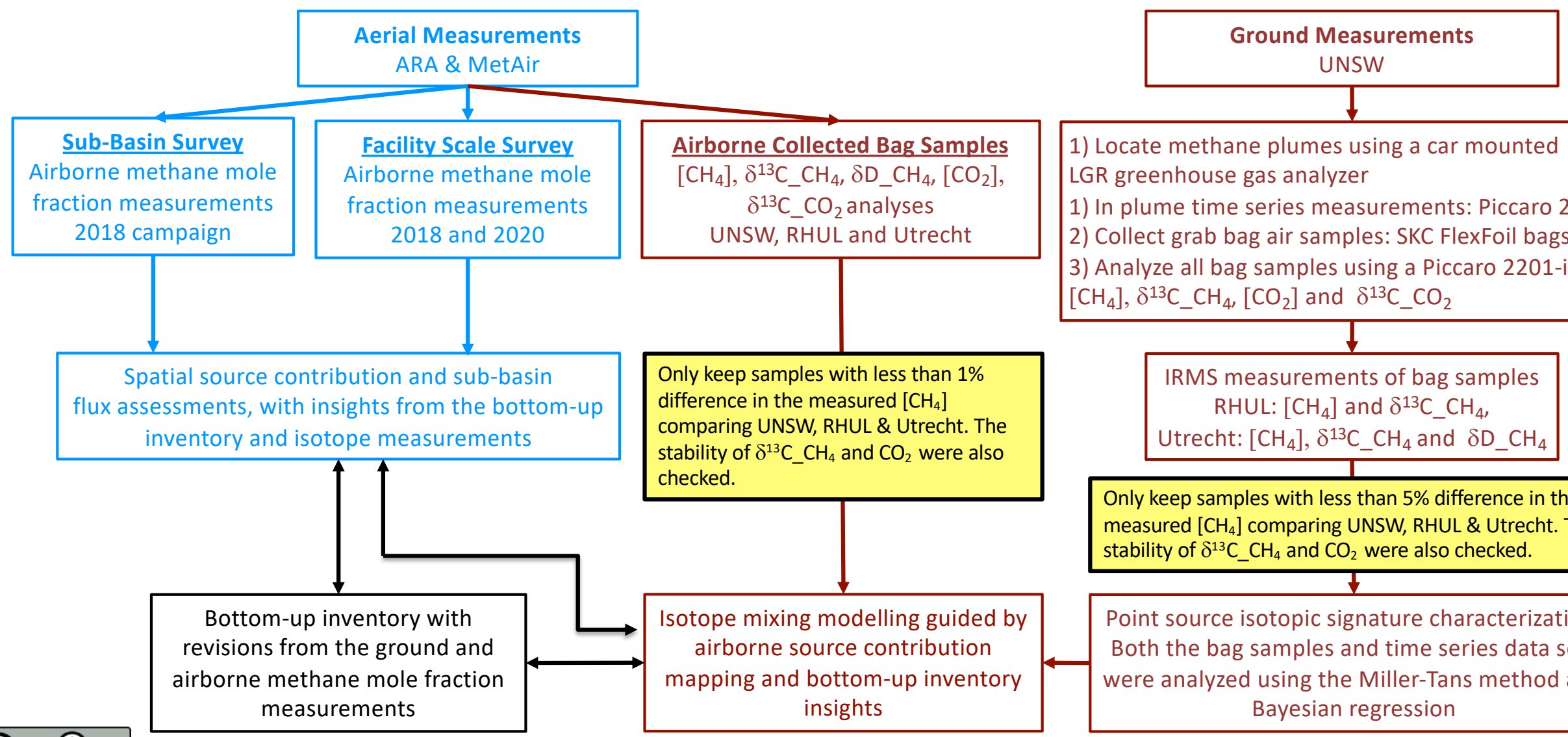

1) Locate methane plumes using a car mounted LGR greenhouse gas analyzer

1) In plume time series measurements: Piccaro 2201-i.

2) Collect grab bag air samples: SKC FlexFoil bags

3) Analyze all bag samples using a Piccaro 2201-i: $\left[\mathrm{CH}_{4}\right], \delta^{13} \mathrm{C}_{-} \mathrm{CH}_{4},\left[\mathrm{CO}_{2}\right]$ and $\delta^{13} \mathrm{C}_{-} \mathrm{CO}_{2}$

Only keep samples with less than $1 \%$

difference in the measured [ $\left[\mathrm{CH}_{4}\right]$

comparing UNSW, RHUL \& Utrecht. The

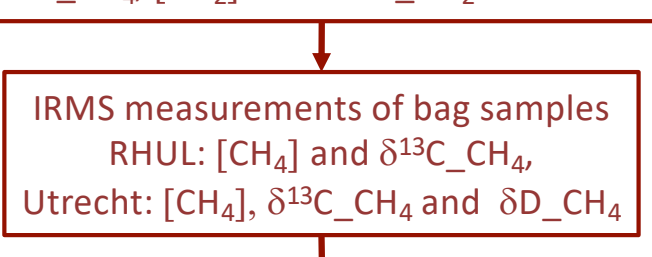

Only keep samples with less than $5 \%$ difference in the measured $\left[\mathrm{CH}_{4}\right]$ comparing UNSW, RHUL \& Utrecht. The stability of $\delta^{13} \mathrm{C}_{-} \mathrm{CH}_{4}$ and $\mathrm{CO}_{2}$ were also checked.

$\checkmark$

Point source isotopic signature characterization. Both the bag samples and time series data sets were analyzed using the Miller-Tans method and Bayesian regression 


\section{Dual Isotope Plot}

The scatterplot of $\delta D_{-} \mathrm{CH}_{4}$ vs $\delta^{13} \mathrm{C}_{-} \mathrm{CH}_{4}$ highlights good separation of sources based on the chemistry of the plume samples.

It is clear in the graph that CSG activity emissions and cattle emissions form distinct clusters. When there is clear end-member chemistry we can use mixing models to apportion contributions.

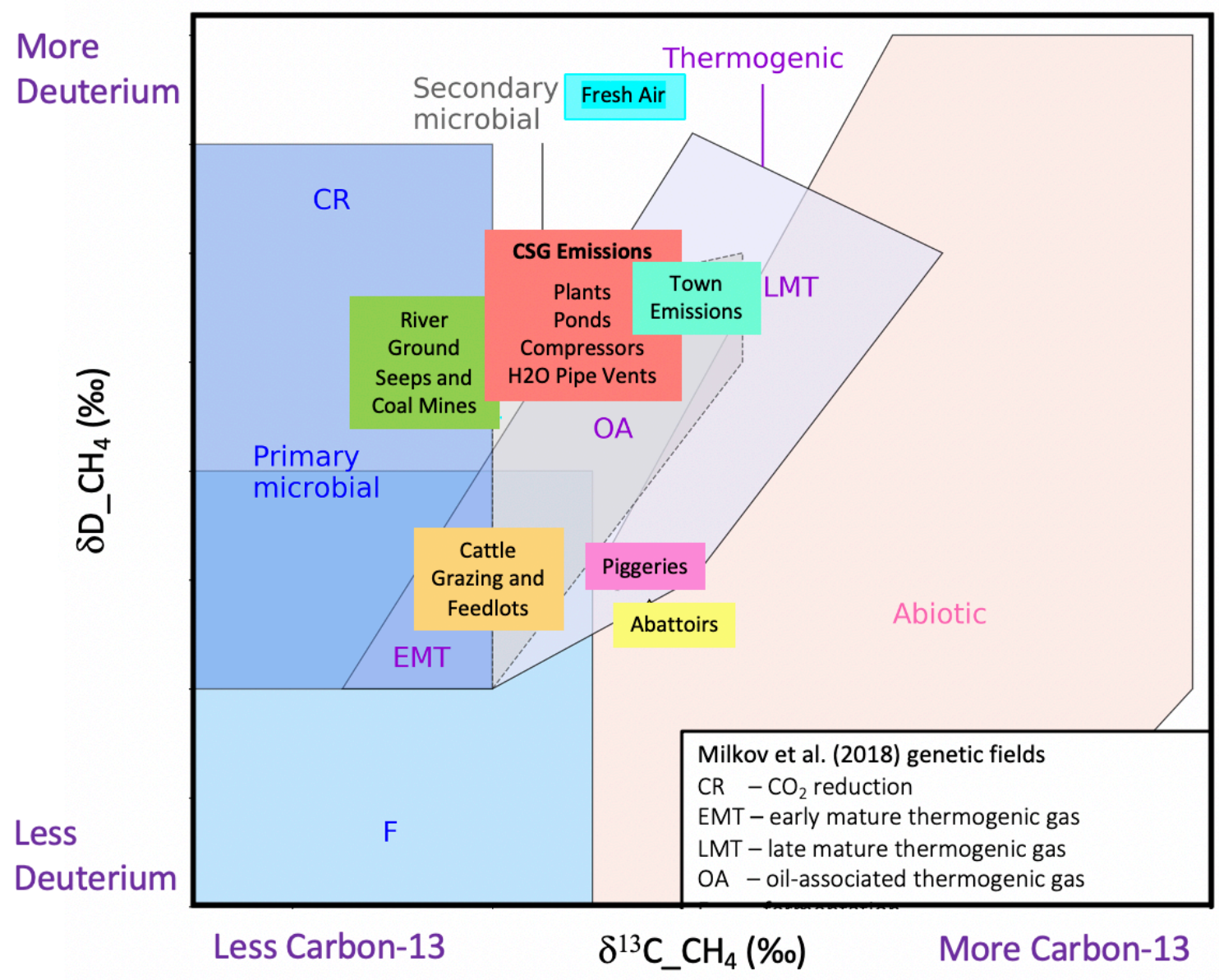




\section{Deuterium Keeling Plot - Ground and Airborne Samples}

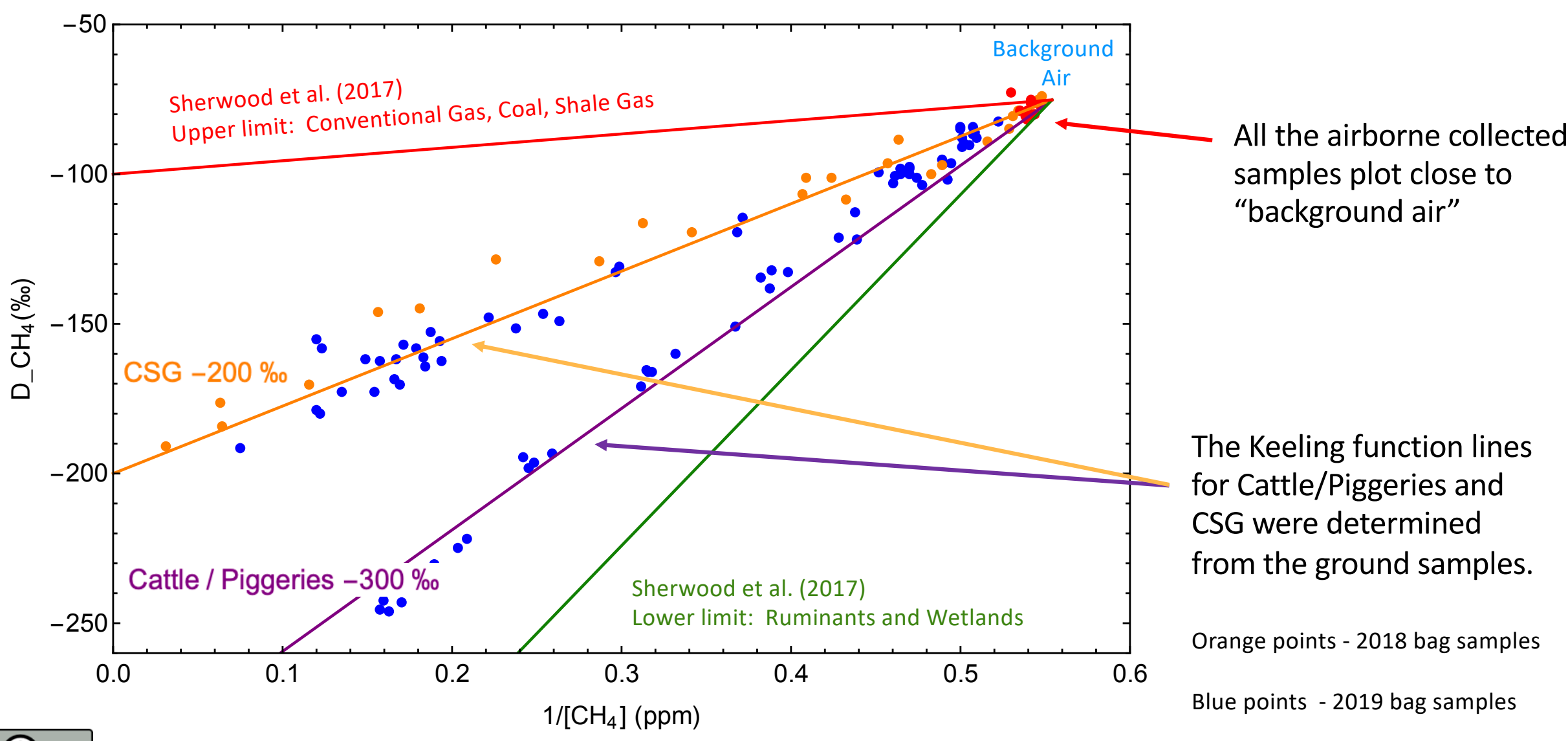




\section{Deuterium Keeling Plot - Airborne Samples}

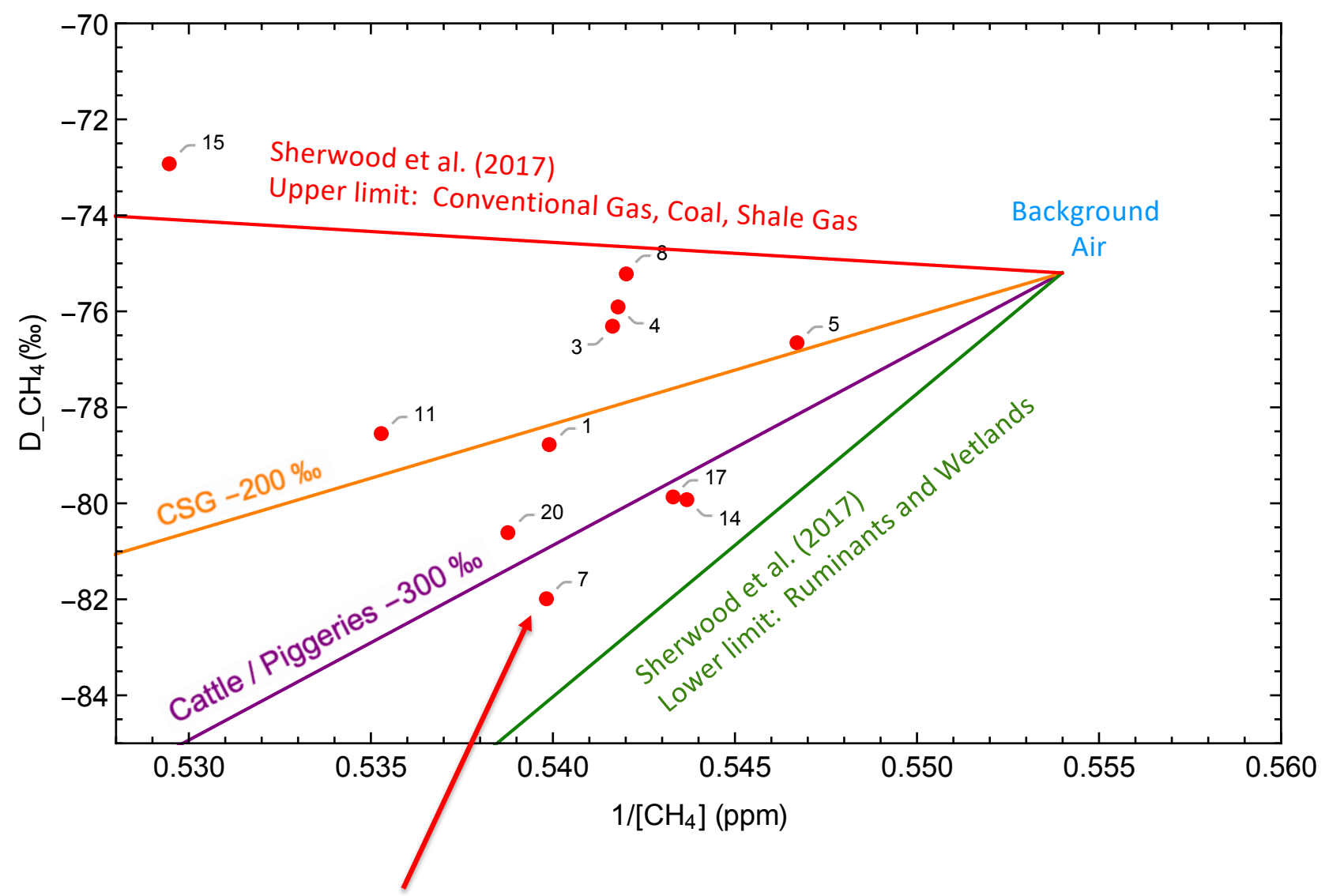

As an example, on the next slide we look closely at potential sources for this bag. 


\section{Airborne Bag Samples - Isotope Mixing Modelling for Source Apportionment}

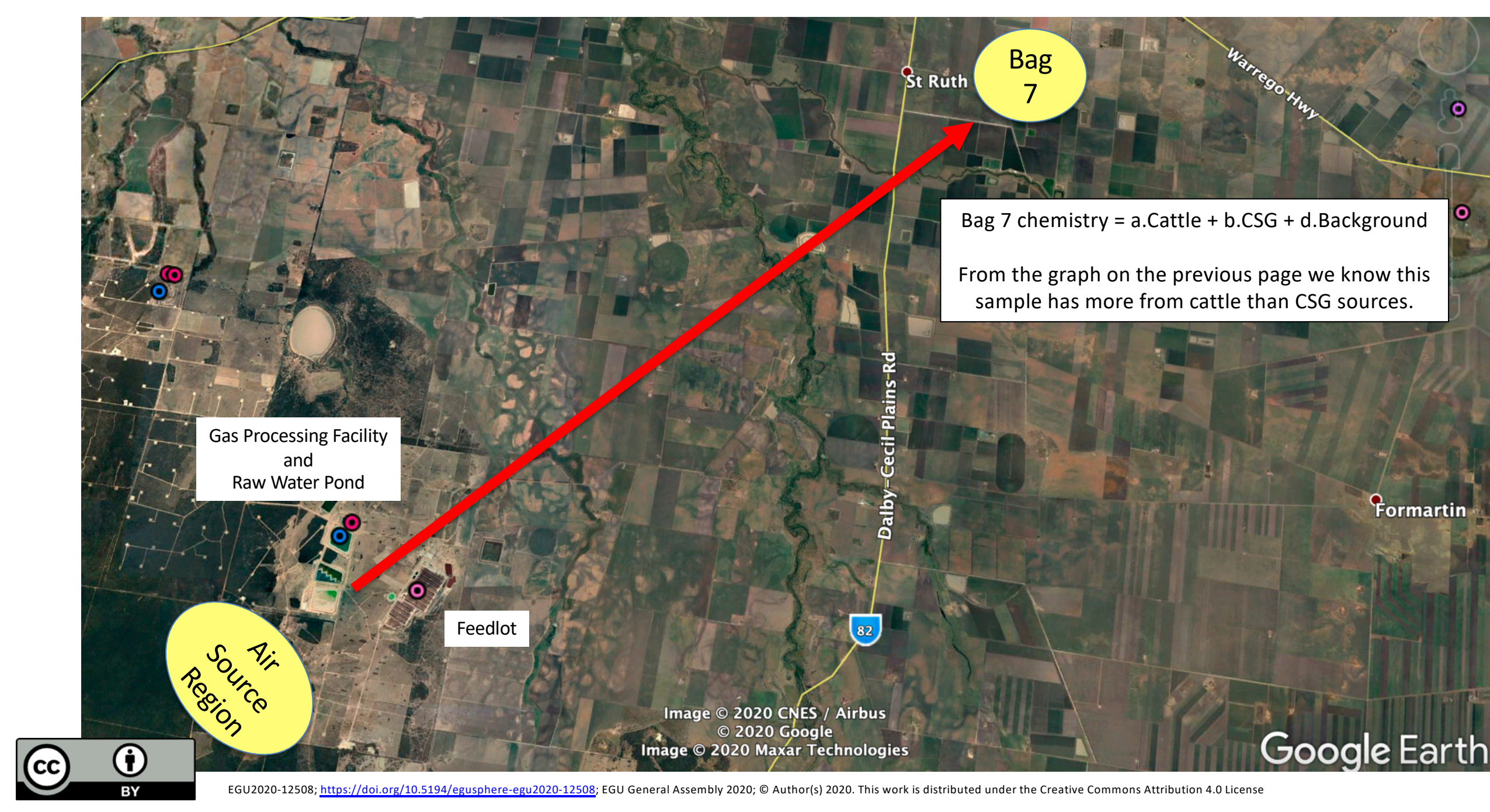




\section{Ongoing Task - Modelling the Airborne FlexFoil Bag Samples}

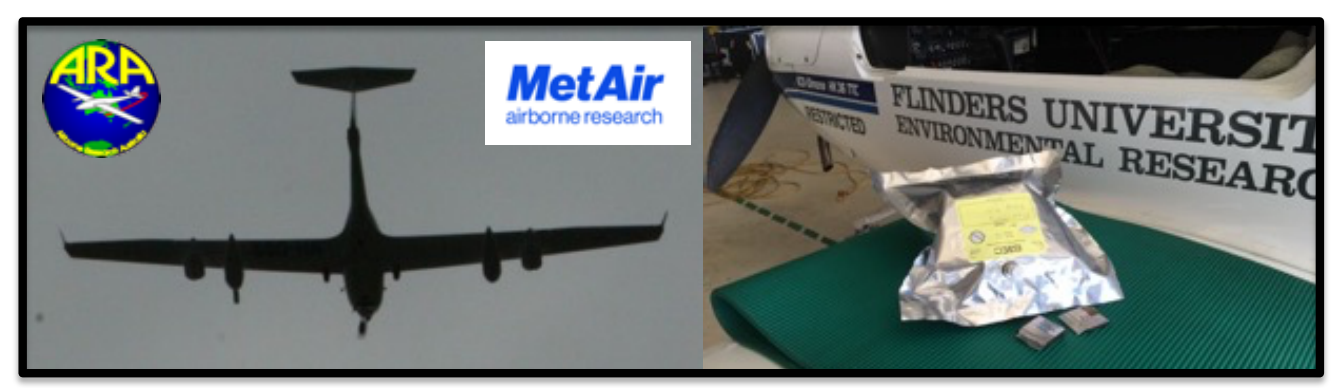

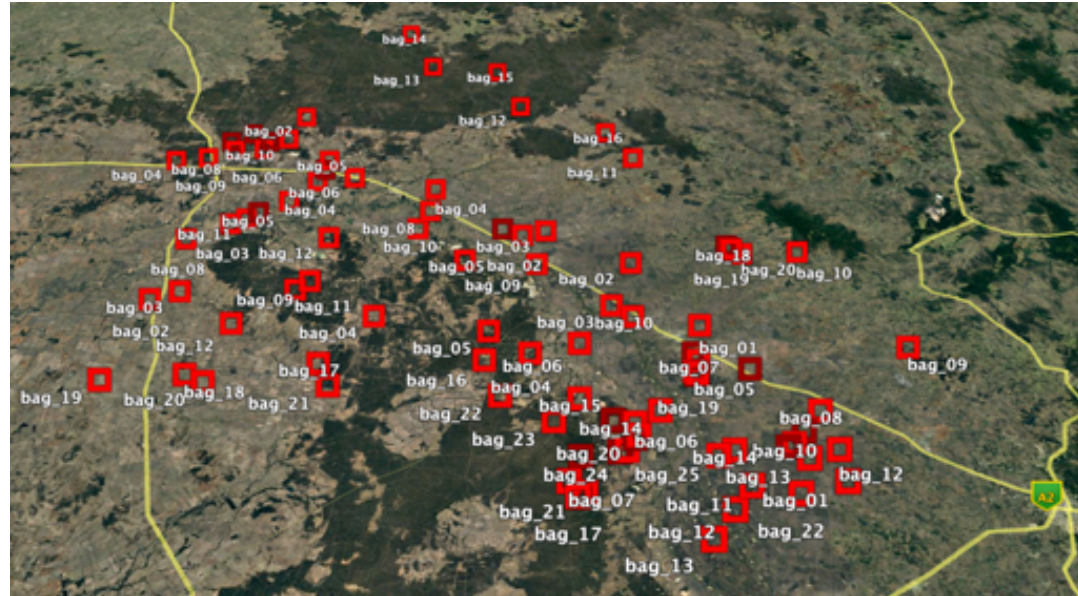

Location of airborne FlexFoil bag samples

The idea of apportionment is schematically simple, but because of the equivalent solutions it is a complex task and depends on many variables, including, but not limited to:

- Distance from source

- Elevation

- Wind speed and direction

- Concentration at source

- Rate of release at source

- Pulsed or continuous

- In-plume vs well-mixed air

- And many more 


\section{Acknowledgement}

\section{Aim: To Reduced Short-Lived Climate Pollutants}

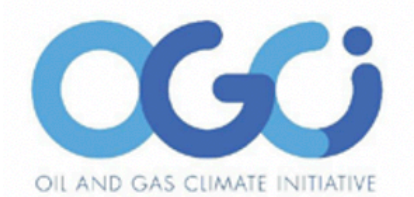

bopen

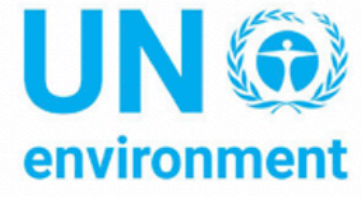

Chevron

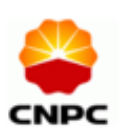

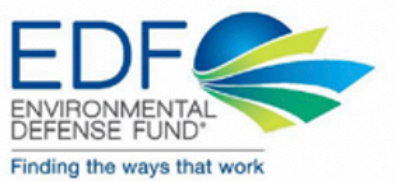

eni

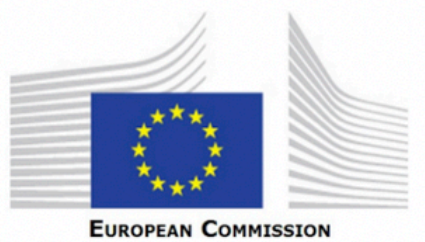

European COMMISSION

$$
\underset{\text { PEMEX PETROBRAS }}{\text { BEPSOL }}
$$

This work was funded under the Climate and Clean Air Coalition (CCAC) Oil and Gas Methane Science Studies (MSS), hosted by the United Nations Environment Programme. Funding was provided by the Environmental Defense Fund, Oil and Gas Climate Initiative, European Commission, and CCAC.

http://ccacoalition.org/en/activity/oil-and-gas-methane-science-studies 